\title{
NEW THICK FILM FUNCTIONAL DEVICES
}

\author{
Y. TAKETA, O. ABE and M. HARADOME \\ Physical Science Laboratories, Nihon University at Narashino, Funabashi, Chiba.
}

\begin{abstract}
The development of thick-film functional devices having oscillation, negative resistance, switching, memory and so on has been needed.

New non-volatile memory devices manufactured of $\mathrm{Nb}_{2} \mathrm{O}_{5}$-based thick-film have now been created. The thick-film devices have been prepared by using common thick-film technology such as screen printing, drying and firing. The characteristics and the operation of the devices are as follows:

When a dc voltage is applied to the devices, rapid resistance change, so called switching effect, occurs. The devices have low resistance state. Even when the voltage is removed completely, the devices do not return to high resistance state and keep low resistance state. However, when alternating voltage is impressed upon the devices, the low resistance state goes to the high resistance state. The recovery time of the resistance state depends upon the frequency of applied ac voltage. The higher frequency voltage that is applied, the sooner the recovery time becomes. The threshold voltage exponentially increases with higher frequency of an applied ac voltage.

In addition to the memory effect, the $\mathrm{Nb}_{2} \mathrm{O}_{5}$-based thick-film devices have a switching and oscillation characteristic.
\end{abstract}

\section{INTRODUCTION}

Thick-film technology is now extensively used for various purpose in hybrid microelectronics manufacturing. Usually the technology, however, is only used for making passive elements such as resistors, conductors, over glaze film etc. ${ }^{1}$ Sometimes thick-film capacitors and thermistors are produced and used as one of the constituent parts of the thick-film hybrid IC. ${ }^{2,3}$ Recently, functional devices having oscillation, amplification, switching, memory and so on have widely been tried to conduct by using thick-film technology. ${ }^{4}$

Researches on the functional devices are being made on oxides such as iron, vanadium, and niobium, which exhibit resistance change under the supply of the joule heating of the oxide when an external voltage is applied between the electrodes. These resistance changes are accompanied by a discontinuous change in the resistivity by a factor of the order of $10^{3}$ through $10^{5}$. Conducting without an applied voltage is by an activated process with a band gap similar to an insulator, and with an applied voltage the band gap is similar to an intrinsic semiconductor. Up to now, for instance, the application of thick-film technology has been made to the development of functional devices, transistors, oscillation devices and switching elements. ${ }^{5}$

By study in $\mathrm{NbO}_{\mathrm{x}}$-based functional devices, then, it has become clear that the devices are characterized as follows:

1) The abrupt switching action occurs when a dc voltage is applied to the specimen, and the resistance changes from high resistance to low resistance.

2) The resistance of the specimen after the switching action is kept low without electrical power.

3) It was found that the $\mathrm{NbO}_{x}$ thick-film devices have a new non-volatile memory effect and can be used as thick-film memory devices.

4) By applying ac voltage memory state can be eliminated. In the following, an interpretation of the physical processes associated with the $\mathrm{NbO}_{\mathrm{x}}$-based thick-film functional devices is described.

\section{PREPARATION OF THE SPECIMENS}

The powder mixed in the ratio $87 \mathrm{Nb}_{2} \mathrm{O}_{5}$ and $13 \mathrm{~V}_{2} \mathrm{O}_{5}$ in $\mathrm{wt} \%$ was presintered for $3 \mathrm{hr}$ at $1300^{\circ} \mathrm{C}$ in air and then pulverized. The resultant powder and glass frits were mixed with the ratio of 80 to $20 \mathrm{wt} \%$. They were evenly dispersed into the organic vehicle to produce printable thick-film inks, screen-printed on $96 \%$ alumina substrate, and fired at $750^{\circ} \mathrm{C}$ for $15 \mathrm{~min}$. in air.

The shape and dimension of the specimen having $3 \mathrm{~mm}$ in width, $4 \mathrm{~mm}$ in length and 40 through $50 \mu \mathrm{m}$ in average thickness is illustrated in Figure 1. The 

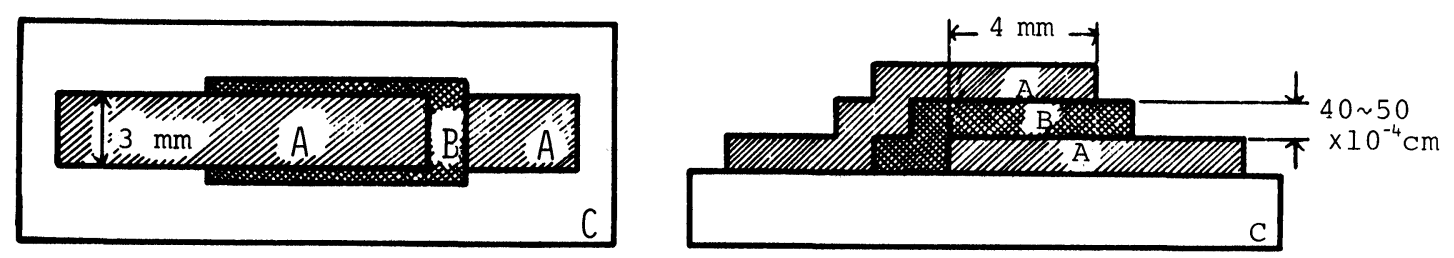

FIGURE 1 Shape and size of specimen. $A=$ electrode; $B=$ specimen; $C=$ substrate.

Pd-Ag thick-film conductor which had previously been prefired on the substrate was used as electrode.

Then, the forming operation for as-fired specimens was performed. The forming operation is that high dc voltage is applied several times to each specimen for a few seconds. 80 to 100 volts for forming is applied in this experiment. After forming, various kinds of electrical measurements were conducted.

\section{RESULTS AND DISCUSSION}

Figure 2 shows the V-I characteristics of the specimen. When the V-I curves were obtained, the resistor was used in series with the specimen to limit the current. The V-I characteristic shows that a) the resistance change is Ohmic, when the voltage is pressed upon the specimen, which is approximately $3 \mathrm{M} \Omega$, and b) with increase in applied voltage non-Ohmic electrical conduction appears and the current increases up to point $A$. Point $A$ is the threshold point, which is typically of the order of about $160 \mathrm{~V} / \mathrm{cm}(\mathrm{Vth}=63 \mathrm{~V}$ in this figure).c) $\mathrm{AC}$ is the negative resistance region. The abrupt switching action (hereinafter called forward switch) occurs in the interval $\mathrm{AB}$, and then current

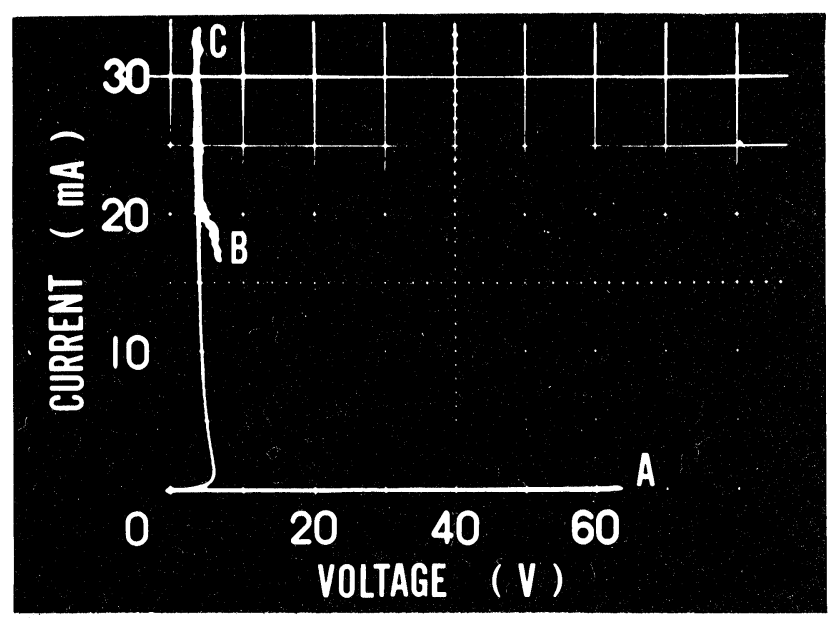

FIGURE 2 DC V-I characteristics.

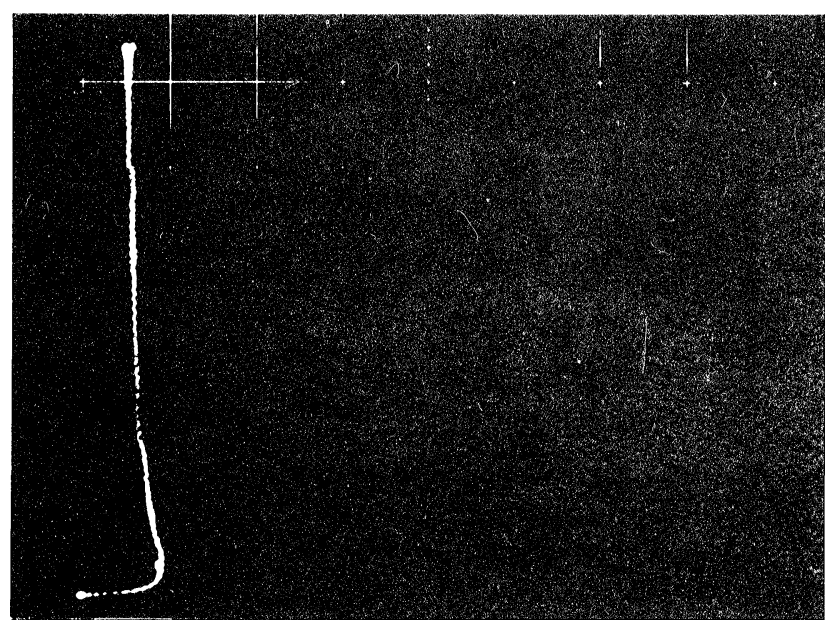

FIGURE 3 DC V-I characteristic for the low resistance state after switching. Horizontal scale is $10 \mathrm{~V} / \mathrm{div}$ and vertical scale $5 \mathrm{~mA} / \mathrm{div}$.

moves to point $C$ very slowly. The change of the resistance in the interval $\mathrm{AB}$ of the specimen is a factor of $10^{3}$ through $10^{4}$. The switching speed is 5 through $10 \mu \mathrm{sec}$ at room temperature. d) With decrease of the current, the curve $\mathrm{CO}$ follows. After the forward switch the resistance of the specimens does not return to high resistance and always holds low value without electrical power. When the voltage is applied to the specimen after switching, the current increases along the curve $D C$ as seen in Figure 3 and the current flow along the curve O-A-B-C is not observed. In order to obtain a high resistance state, alternating voltage is applied to the specimen. So the low resistance state readily returns to the high resistance state. Therefore, the high resistance is in a state of memory and a quick conversion from memorized state to non-memorized state is taken place by applying ac voltage. That is to say, the specimen has a non-volatile memory effect.

Figure 4 illustrates ac voltage-current characteristics. When the ac voltage (sine wave $50 \mathrm{~Hz}$ ) is impressed upon the specimen keeping the low resistance state is gradually increased, the current also increases. After 


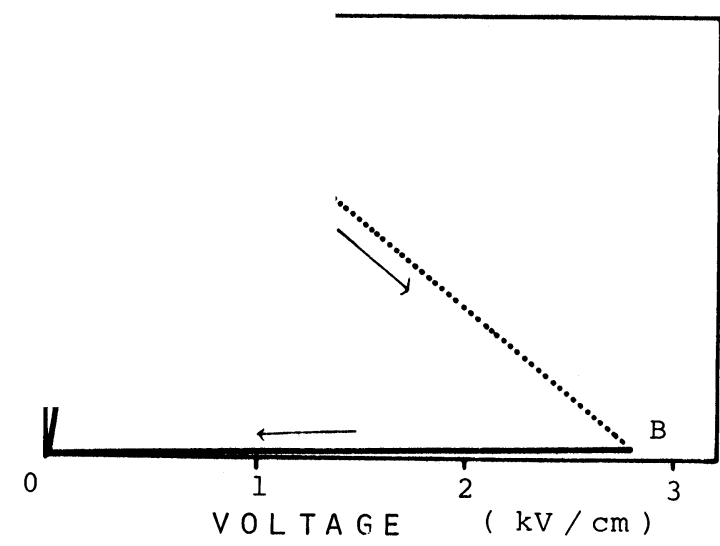

FIGURE 4 AC V-I characteristics.

passing through the point $\mathrm{A}$, the abrupt switching action (hereinafter called backward switch) occurs in the interval $A B$ and the current rapidly decreases. In this case, when the current reaches $9 \mathrm{~mA}$ (applied voltage, ac $3.5 \mathrm{~V}$ ), a backward switching occurs and the current changes to $7 \mu \mathrm{A}$ (applied voltage, ac $14 \mathrm{~V}$ ). The backward switching speed is relatively slow and roughly 100 through $200 \mathrm{msec}$. The resistance changes from $200 \Omega$ at the low resistance state to $20 \mathrm{M} \Omega$ at the high resistance state. With the electronic devices it is required that there is no temperature dependence of the electronic properties. So in the next study, we examined how the ambient temperature would affect the resistance of the specimens. Figure 5 shows the temperature dependency of the resistance. The specimen has the temperature dependency as seen this figure. For example, in the case of the specimen applying $10 \mathrm{~V}$, when the ambient temperature elevates up to $80^{\circ} \mathrm{C}$, the resistance changes quickly in the factor of $10^{3}$. From this experiment it is found that the resistance change of the specimen is accompanied by irregular oscillation (afterward we describe). Figures 6 and 7 show the temperature dependency of the V-I characteristics and the relation between the threshold voltage and the temperature respectively. Above $100^{\circ} \mathrm{C}$ the negative resistance is no longer seen in the V-I characteristic curve. That curve shows only the positive resistance. Above $80^{\circ} \mathrm{C}$, the switching actions also disappears. Vth decreases with increase in ambient temperature and at the same time as seen in Figure 6. The areas of the hystersis loop of the V-I characteristic curve also decrease. The gradient (that is OC part as seen in Figure 2) of the V-I characteristic curves after switching changes from negative inclination to a positive one with the increase in the temperature. As

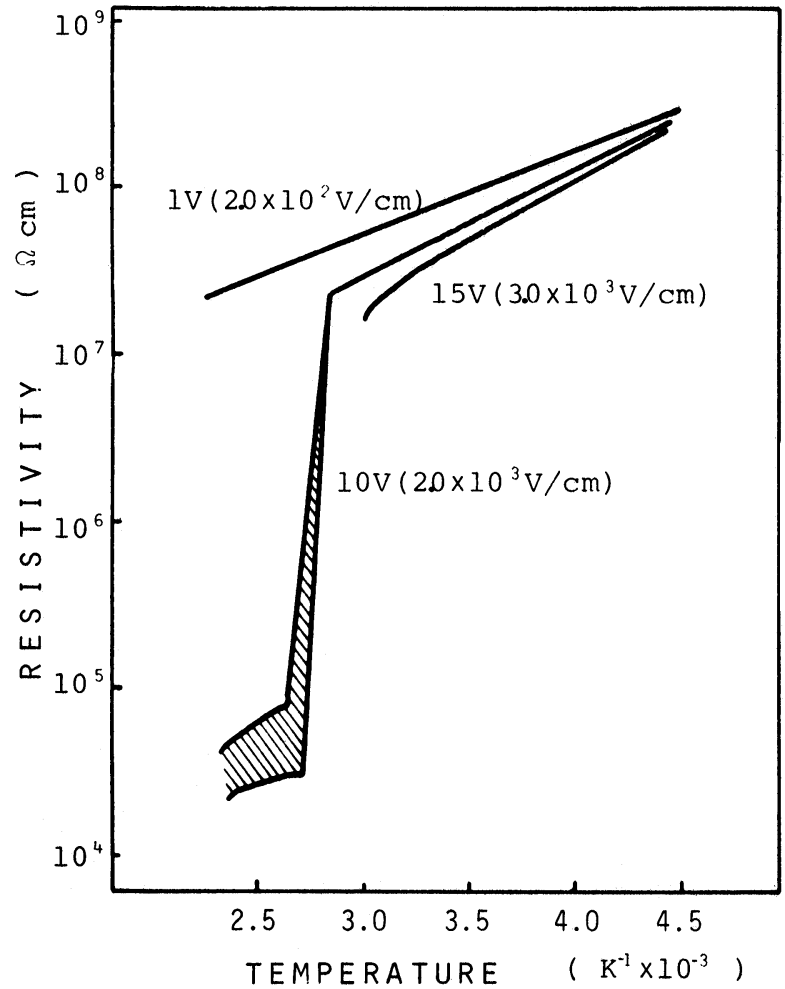

FIGURE 5 Temperature dependence of the resistance. The shadowed portion shows the area of oscillation.

seen in this figure, threshold voltage is in proportion to the reciprocals of the temperature.

On the other hand, each switching speed of forward and backward switch also depends upon the ambient temperature. Also the threshold voltage changes with the ambient temperature. The temperature dependency of the forward switch is illustrated in Figure 8. The switching speed of forward switching is about 5 through $10 \mu \mathrm{sec}$ at room temperature but the switch speed increases 200 through $250 \mu \mathrm{sec}$, when the atmosphere temperature decreases from room temperature to $-50^{\circ} \mathrm{C}$. The switching speed becomes roughly constant value below about $-80^{\circ} \mathrm{C}$. The backward switch has the same tendency, too. The switching speed of backward switch is about 100 through $200 \mathrm{msec}$ at room temperature and increases 1 through $1.5 \mathrm{sec}$ at about $-150^{\circ} \mathrm{C}$. We investigated the relation between backward switch time and applied voltage when ac voltage was suddenly impressed upon the specimen with keeping the low resistance state. Figure 9 shows how backward switching time is changed by applying ac voltage. From these results, it was found that the switching time is proportional to the applied voltage. For instance, when ac $4 \mathrm{~V}$ 

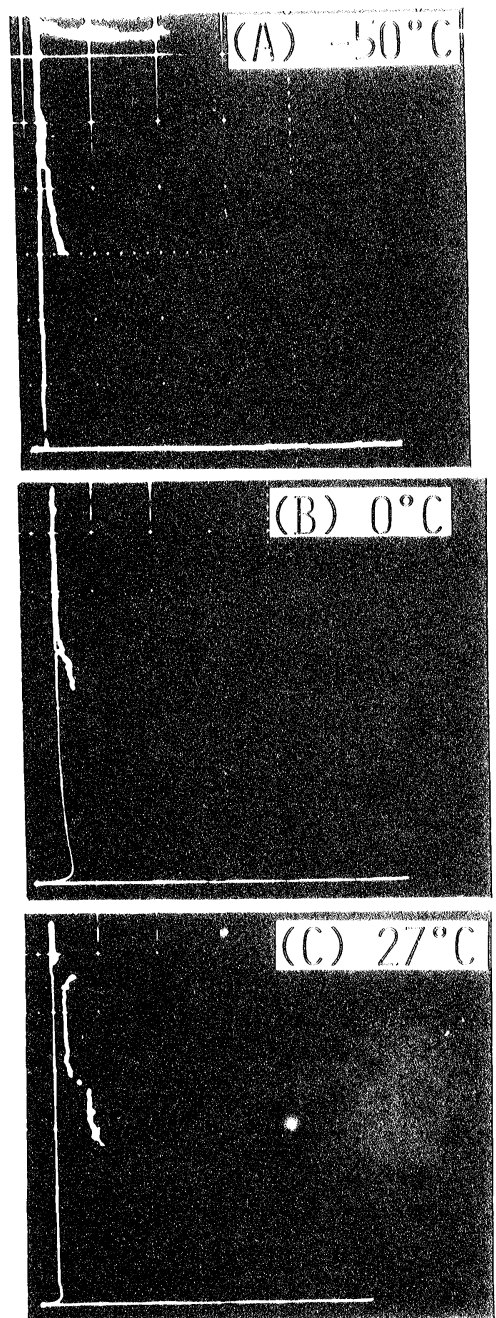

FIGURE 6 Temperature dependence of V-I characteristics. Horizontal scale is $5 \mathrm{~mA} / \mathrm{div}$ and vertical scale $10 \mathrm{~V} / \mathrm{div}$.

$\left(8 \times 10^{2} \mathrm{~V} / \mathrm{cm}\right)$ is applied to the specimen, the switching time is about $10 \mathrm{msec}$ and in the case of ac $8 \mathrm{~V}\left(1.6 \times 10^{3} \mathrm{~V} / \mathrm{cm}\right)$ it is about $10 \mu \mathrm{sec}$.

As mentioned above, when the transition of the resistance occurs, the oscillation is always observed in the specimen. Thereby, the oscillation phenomenon was examined by applying pulse-like voltage to the specimen to avoid evolution of heat as much as possible. The pulse-like voltage used is $150 \mathrm{~V}$, width $20 \mu \mathrm{sec}$ and pulse form is rectangular. Figure 10 shows the oscillation characteristics. The oscillation amplitude is 30 through $70 \mathrm{~V}$, frequency $200 \mathrm{kHz}$ through $2 \mathrm{MHz}$ and the oscillation waveform is blocking-like, and this oscillation is characterized in self oscillation of $\mathrm{Nb}_{2} \mathrm{O}_{5}$-based thick-film. The amplitude and the

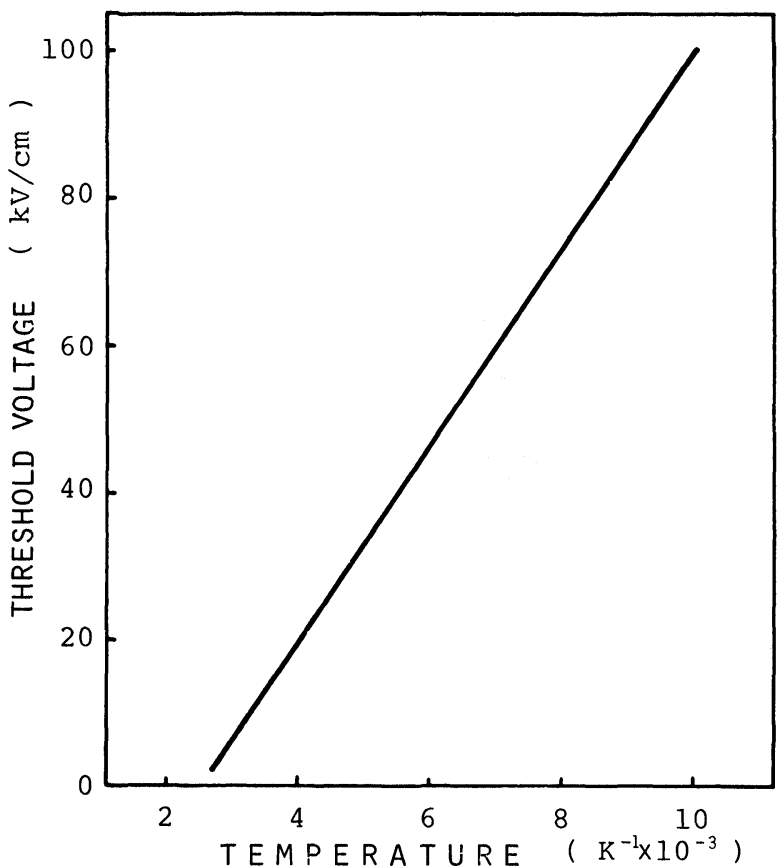

FIGURE 7 Relation between ambient temperature and threshold voltage.

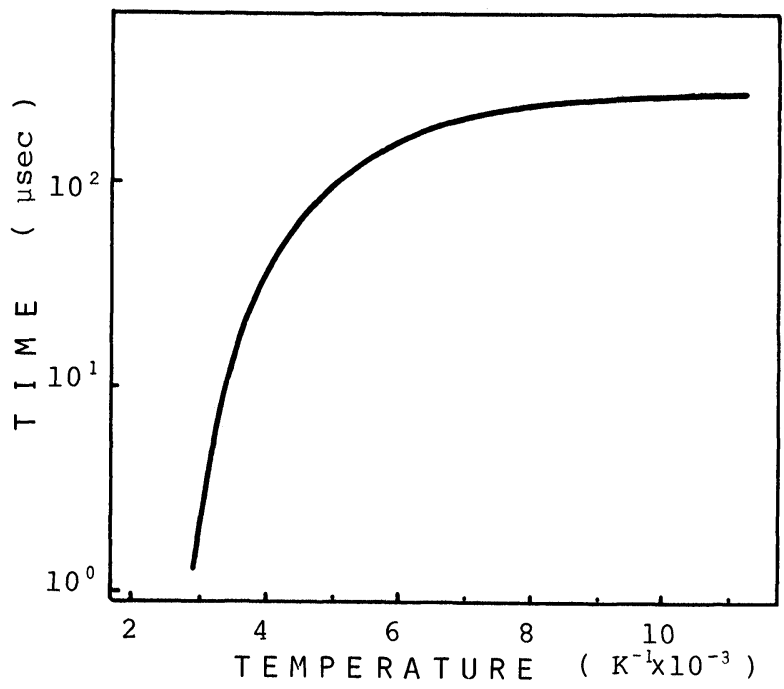

FIGURE 8 Temperature dependence of the switching speed.

frequency of the oscillation strongly depend upon the environmental temperature as indicated in Figure 11. The oscillation is remarkable especially in the region of the temperature between -50 and $80^{\circ} \mathrm{C}$. In this region, the frequency of the oscillation increases only slightly but the amplitude decreases relatively large from about $110 \mathrm{~V}$ to $60 \mathrm{~V}$ in inverse proportion to the ambient 


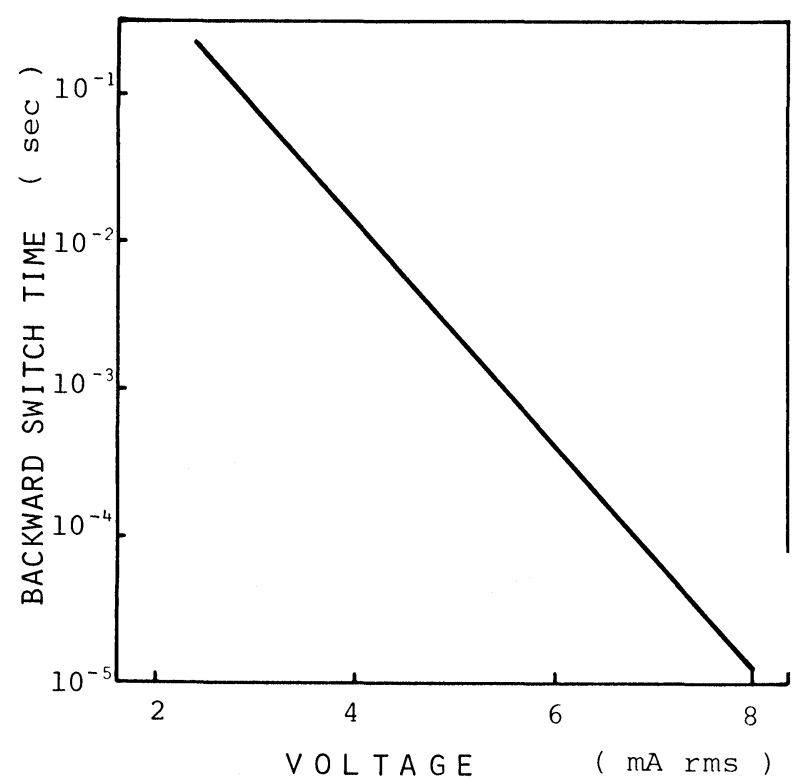

FIGURE 9 Relation between applied voltage and backward switch time.
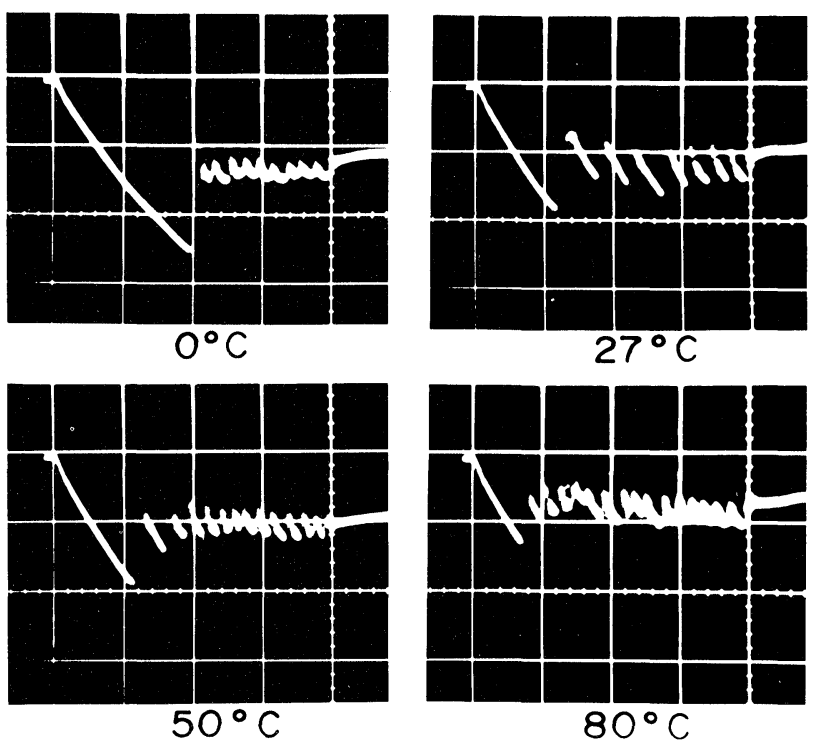

FIGURE 10 Temperature dependence of oscillation characteristics. Horizontal scale is $50 \mathrm{~V} / \mathrm{div}$ and vertical $5 \mu \mathrm{sec} / \mathrm{div}$.

temperature. The relation between the oscillation beginning voltage and the ambient temperature of the specimen is shown in Figure 12. As the ambient temperature increases, a sharp drop in the threshold voltage occurs. For example, when the temperature is $-100,24$ and $100^{\circ} \mathrm{C}$, the oscillations appear at 480,98 and $32 \mathrm{~V}$, respectively.

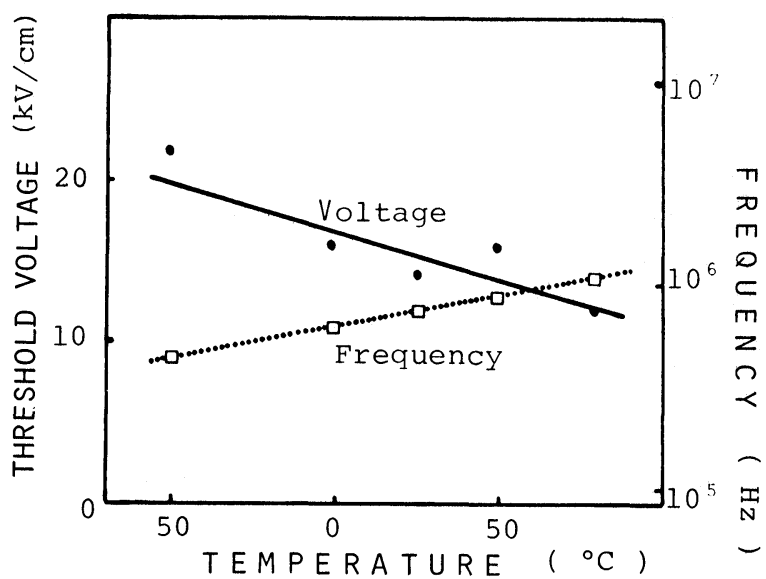

FIGURE 11 Temperature dependence of oscillation characteristics.

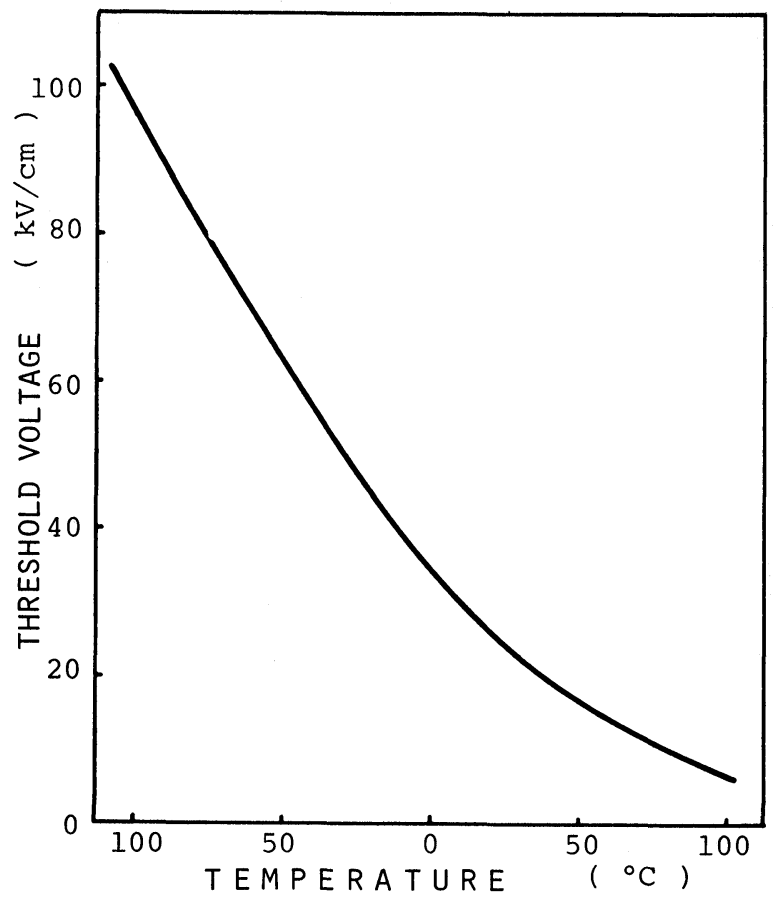

FIGURE 12 Temperature dependence of threshold voltage.

The study of the memory effect and oscillation phenomena in the $\mathrm{Nb}_{2} \mathrm{O}_{5}$-based thick-film is just in its initial phase, and consequently serious discussion of a mechanism will be premature. In the view of the X-ray diffraction analysis the structure of the specimen consists of $(\mathrm{Nb}, \mathrm{V})_{2} \mathrm{O}_{5}, \mathrm{NbVO}_{3}$, and $\alpha-\mathrm{Nb}_{12} \mathrm{O}_{29}$ crystallites. In the case of oxide materials having the switching effect, thermal filaments or channels are 
usually formed. However, these thermal phenomena have not been observed in our specimen yet. A delay time of the switching or oscillation action with input signal is found, and the temperature at which these phenomena can be observed is lower than the temperature (the region of about $800^{\circ} \mathrm{C}$ ) at which $\mathrm{Nb}_{2} \mathrm{O}_{5}$ shows the sharp change in the electrical resistance. This seems that the filament or channel is the most probable affecting factor for these phenomena and thermal energy probably has direct effect upon the oscillation and memory phenomena.

Further studies, especially of the memory and oscillation mechanism, are being pursued and will be published in the near future.

\section{CONCLUSIONS}

The $\mathrm{Nb}_{2} \mathrm{O}_{5}$-based functional devices having memory, oscillation, switching and so on were made by using thick-film technology.

The properties of the memory and oscillation effects are as follows:

1) The memory is non-volatile memory phenomenon.
2) The memory state of these devices can be converted into the unmemorized state by applying ac voltage.

3) The oscillation is the self-oscillation and the waveform is blocking-like.

4) The frequency of this oscilation and memory phenomena are influenced by the ambient temperature and the dimension of the specimen.

\section{REFERENCES}

1. C. A. Harper (Ed) Handbook of Thick-Film Hybrid Microelectronics, McGraw-Hill Book Company, New York (1974).

2. Y. Taketa, et al, 'Thick-Film Thermistors', Journal of the College of Industrial Technology Nihon University, 9-1, 109 (1976).

3. A. Ikegami, et al, 'Thick-Film Thermistor', Ceramics, 14, 220 (1979).

4. Y. Taketa, et al, 'New Thick-Film Oscillation Devices', Proceedings Hybrid Microelectronics Symposium, 445 (1975). 

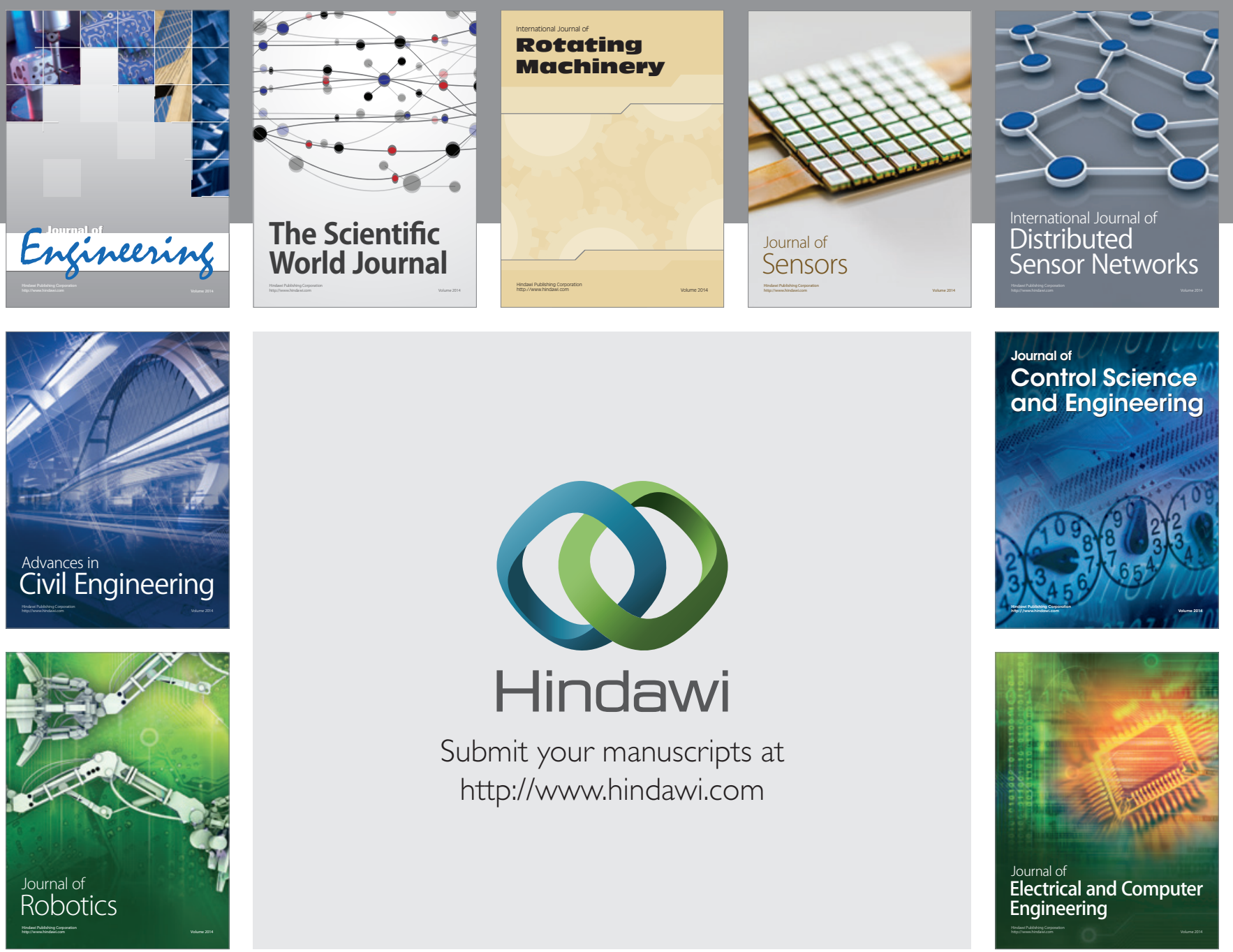

Submit your manuscripts at

http://www.hindawi.com
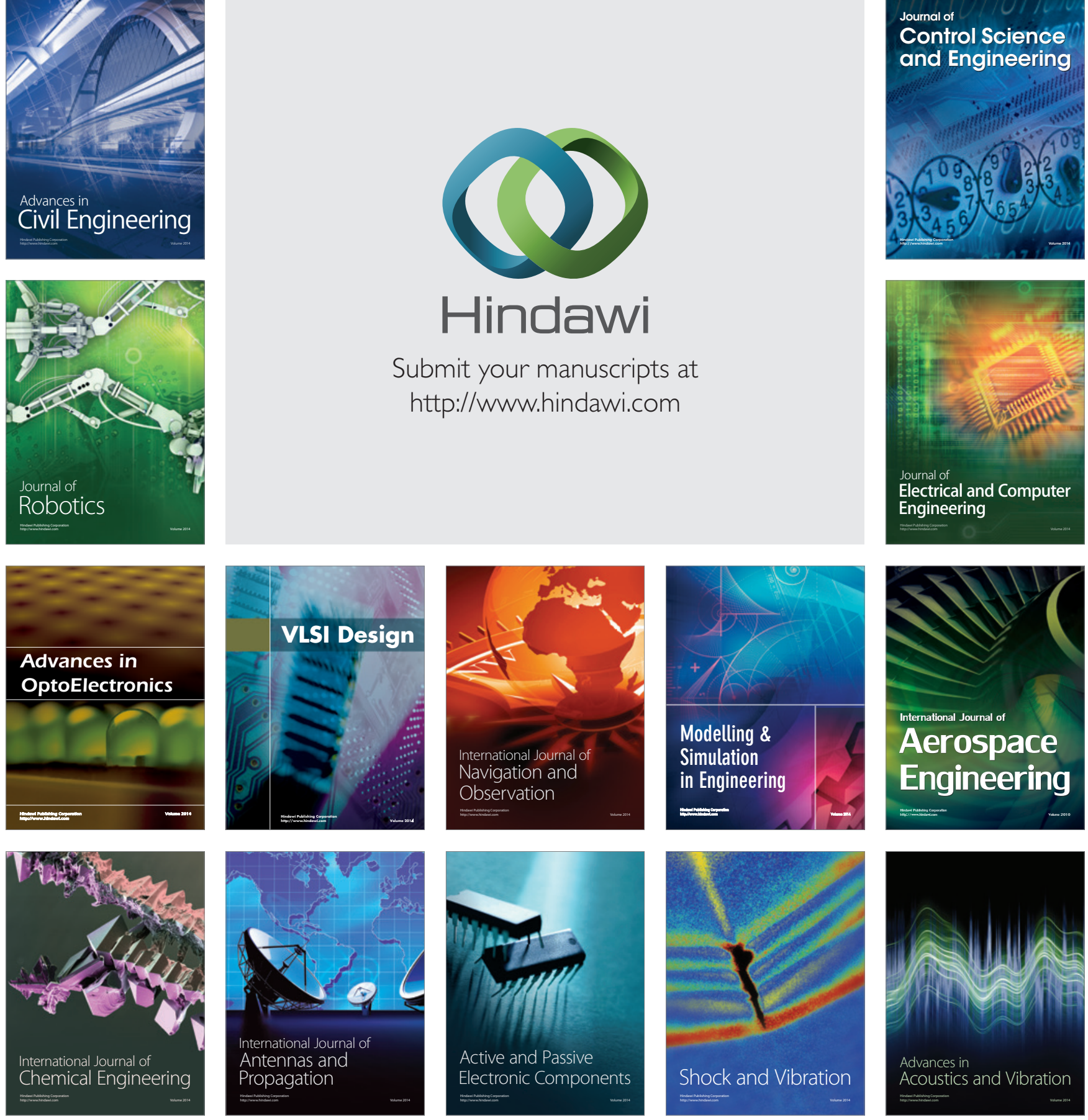